Research Paper

\title{
Microencapsulation of Bifidobacterium animalis subsp. lactis and Lactobacillus acidophilus in cocoa butter using spray chilling technology
}

\author{
D.L. Pedroso, M. Dogenski, M. Thomazini, R.J.B. Heinemann, C.S. Favaro-Trindade \\ Faculdade de Zootecnia e Engenharia de Alimentos, Universidade de São Paulo, \\ Pirassununga, SP, Brazil.
}

Submitted: March 23, 2012; Approved: November 13, 2012.

\begin{abstract}
In the present study, the cells of Bifidobacterium animalis subsp. lactis (BI-01) and Lactobacillus acidophilus (LAC-04) were encapsulated in cocoa butter using spray-chilling technology. Survival assays were conducted to evaluate the resistance of the probiotics to the spray-chilling process, their resistance to the simulated gastric and intestinal fluids (SGF and SIF), and their stability during 90 days of storage. The viability of the cells was not affected by microencapsulation. The free and encapsulated cells of B. animalis subsp. lactis were resistant to both SGF and SIF. The microencapsulated cells of $L$. acidophilus were more resistant to SGF and SIF than the free cells; the viability of the encapsulated cells was enhanced by $67 \%$, while the free cells reached the detection limit of the method $\left(10^{3} \mathrm{CFU} / \mathrm{g}\right)$. The encapsulated probiotics were unstable when they were stored at $20^{\circ} \mathrm{C}$. The population of encapsulated L. acidophilus decreased drastically when they were stored at $7{ }^{\circ} \mathrm{C}$; only $20 \%$ of cells were viable after 90 days of storage. The percentage of viable cells of the encapsulated $B$. animalis subsp.lactis, however, was $72 \%$ after the same period of storage. Promising results were obtained when the microparticles were stored at $-18{ }^{\circ} \mathrm{C}$; the freeze granted 90 days of shelf life to the encapsulated cells. These results suggest that the spray-chilling process using cocoa butter as carrier protects $L$. acidophilus from gastrointestinal fluids. However, the viability of the cells during storage must be improved.
\end{abstract}

Key words: probiotic, spray cooling, spray congealing, lipid matrix, solid lipid microparticles.

\section{Introduction}

There is considerable scientific and commercial interest in the use of probiotic bacteria. Probiotics are live microorganisms that confer health benefits to the host when administered at adequate levels (FAO WHO, 2006). However, to exert these benefits, the microorganisms must remain viable during the processing and storage of food and must be resistant to gastrointestinal fluids (Favaro-Trindade et al., 2011). Because probiotics are sensitive to a number of factors, including the presence of oxygen and acidic media, microencapsulation has been studied as a method of increasing the viability of probiotic cells (Favaro-Trindade and Grosso, 2002; Fung et al., 2011; Kim et al., 2008; Kwok et al. (1992); Oliveira et al. (2007) a and b; Okuro et al. (2013)a).
Microencapsulation of probiotics is a process that surrounds probiotic microorganisms in a polymeric membrane, protecting them and, in certain cases, allowing their release under specific conditions. The techniques commonly applied to encapsulate probiotics are extrusion, atomization or spray drying, emulsion, coacervation and immobilization in fat or starch granules (Favaro-Trindade et al., 2011). Polysaccharides, such as alginate, gellan, $\kappa$-carrageenan, and starch are the most commonly used materials in the microencapsulation of bifidobacteria and lactobacilli (Rokka and Rantamaki 2010). Lahtinen et al. (2007), however, immobilized bifidobacteria in a lipid matrix of cocoa butter. This process resulted in the increased viability of the cells during storage in model systems that simulated fermented and unfermented beverages. This result suggests that the lipid matrix protects cells against stor- 
age stress and may shield them from exposure to water and stressors, such as $\mathrm{H}^{+}$ions. Furthermore, due to the composition of lipid materials, they are easily digested in the intestine by lipases, which release the encapsulated microorganisms (Favaro-Trindade et al., 2011). Therefore, the incorporation of probiotics into lipid microparticles is an interesting approach for food products.

Spray chilling technology (also called spray cooling or spray congealing) uses lipids as wall materials. This process is similar to spray drying with respect to the production of fine droplets. However, spray chilling is based on the injection of cold air, which enables the solidification of the particle; a molten matrix that contains the bioactive compound is atomized such that it forms drops that quickly solidify when they contact the cold air (Champagne and Fustier 2007; Okuro et al., 2013b). The spray chilling process is typically referred to as matrix encapsulation in the literature because the microcapsules present a structure in which the core material is homogeneously distributed throughout the carrier material (Rokka and Rantamaki, 2010; Okuro et al., 2013b).

The microparticles that are produced by this process can present a number of disadvantages, which include a low encapsulation capacity and the expulsion of core material during storage due to the crystalline structure and polymorphic arrangement characteristic of many lipid materials during the solidification and crystallization process (Westesen et al., 1997; Sato and Ueno, 2005). However, spray chilling is considered to be the cheapest encapsulation technology that can be used in industrial-scale manufacture (Westesen et al., 1997; Gouin, 2004; Sato and Ueno, 2005). According to Champagne and Fustier (2007), spray chilling deserves greater consideration as a means of microencapsulation of probiotics because it may expand the range of matrices that are used. Moreover, this technology could be used to generate smaller beads, which may be desirable in food processing.

To date, spray chilling has been applied for conserving enzymes, flavors, minerals, and proteins (de Vos 2010). In previous works our group used spray chilling to produce microparticles of B.animalis subsp. lactis and $L$. acidophilus using an interesterified fat with palm and palm kernel as carrier (Pedroso et al., 2012; Okuro et al., 2013a). In this work, however, we used a natural carrier with large application in food products. Thus, the aim of this study was to microencapsulate B.animalis subsp. lactis and $L$. acidophilus in cocoa butter using the spray chilling technology.

\section{Materials and Methods}

\section{Carrier}

The cocoa butter, which was kindly donated by Emfal (Betim, Brazil), was used as meltable carrier. It is composed of saturated and unsaturated fatty acids with predom- inance of acid stearic (C18:0) and acid oleic (C18:1). Its melting point is $36.5^{\circ} \mathrm{C}$.

\section{Culture preparation}

B. animalis subsp. lactis (BI-01) and L. acidophilus (LAC-04), which were donated by Danisco (Cotia, Brazil) were activated according to the method described by Liserre et al. (2007), with some modifications. The freeze-dried cultures were activated in reconstituted skim milk $(100 \mathrm{~g} / \mathrm{L})$ that contained 1\% (w/v) glucose, 1\% (w/v) sodium citrate, $1 \%(\mathrm{w} / \mathrm{v})$ yeast extract and $0.05 \%(\mathrm{w} / \mathrm{v})$ cysteine for 20 hours at $37^{\circ} \mathrm{C}$. The cells were harvested by centrifugation at $9,500 \mathrm{rpm}$ for $8 \mathrm{~min}$ and were washed twice in $\mathrm{NaCl}$ solution $(0.85 \% \mathrm{w} / \mathrm{v})$. The pellet was resuspended in the saline solution to obtain a suspension that contained approximately $10^{9}-10^{10} \mathrm{cfu} / \mathrm{g}$. The suspension of free cells was maintained into a glass vessel with cover at $-18^{\circ} \mathrm{C}, 7^{\circ} \mathrm{C}$ and $20^{\circ} \mathrm{C}$ for the future assays of resistance and viability.

\section{Enumeration of cells}

The viable $B$. animalis subsp. lactis and $L$. acidophilus cells were counted by the pour-plate technique on MRS agar according to the method of Grosso and Fávaro-Trindade (2004) with some modifications. For $B$. animalis subsp. lactis MRS agar was supplemented with lithium chloride $(0.1 \%)$, L-cysteine and aniline blue $(0.01 \%)$. Serial dilutions were prepared with a $2 \%$ sodium citrate solution. The plates were incubated in anaerobiosis with the anaerobic system (Probac, São Paulo, Brazil) at $37^{\circ} \mathrm{C}$ for 72 hours. The plating was performed in duplicate. For the enumeration of probiotics in the microparticles, however, a pre-heated sodium citrate solution at $40{ }^{\circ} \mathrm{C}$ was used in order to melt the fat matrix and promote the release of the cells during serial dilutions.

\section{Preparation of microparticles}

The microparticles were prepared with a spray chiller (Labmaq, Sertãozinho, Brazil) according to the method of Chambi et al. (2008) with some modifications. A solution that contained molten cocoa butter (carrier agent), probiotic (the core or active compound) and lecithin (surfactant) was homogenized in an Ultraturrax (IKA, Staufen, Germany) at 9,500 rpm for 60 seconds. Proportions of reactivated cells:cocoa butter (w/w) of 1:10 (B. animalis subsp. lactis) and 1:4 (L. acidophilus) were used to obtain microparticles that contained levels of viable cells of at least $10^{7} \mathrm{cfu} / \mathrm{g}$. The lipid microparticles were subsequently formed by the atomization of the emulsion into a cold chamber at $10{ }^{\circ} \mathrm{C}$ using a double fluid atomiser $(\varnothing=0.7 \mathrm{~mm})$ with an atomization air pressure of $1.0 \mathrm{kgf} / \mathrm{cm}^{2}$. The microparticles were maintained in a freezer for the future assays of resistance and characterization. The microparticles were also maintained at $-18^{\circ} \mathrm{C}, 7^{\circ} \mathrm{C}$ and $20^{\circ} \mathrm{C}$ for the shelf-life assays. 


\section{Characterization of microparticles}

The morphologies of the microparticles were evaluated using scanning electron microscopy (SEM) (JSM, Jeol, Tokyo, Japan) according to Oliveira et al. (2007a) and optical microscopy (Bel, Monza, Italy) using a digital camera and the Global Lab Image program (Bel MicroImage Analyzer, Monza, Italy). The particle-size distribution of the microparticles was measured by laser diffraction with Shimadzu Sald-201V (Tokyo, Japan) equipment with ethylic alcohol as the dispersant agent.

Evaluation of the resistance of $B$. animalis subsp. lactis and $L$. acidophilus to the microencapsulation process

To determine the effect of the spray chilling process on the viability of the microorganisms, cell counts were performed before the microencapsulation process (at the emulsion step) and in the microparticles.

\section{Evaluation of the resistance of $B$. animalis subsp. lactis and $L$. acidophilus to simulated gastric and intestinal fluids}

The resistance of the probiotics to simulated gastric fluid (SGF) and simulated intestinal fluid (SIF) in vitro was determined according to the method of Gbassi et al. (2009). Free and encapsulated cells were incubated in SGF for $120 \mathrm{~min}$ and in SIF for $180 \mathrm{~min}$ at $37^{\circ} \mathrm{C}$. The SGF consisted of $9 \mathrm{~g} / \mathrm{L}$ of sodium chloride (Synth, Diadema, Brazil) and $3 \mathrm{~g} / \mathrm{L}$ of pepsin from porcine stomach mucosa (SigmaAldrich, St. Louis, USA), and the $\mathrm{pH}$ was adjusted to 1.8 with hydrochloric acid (Synth, Diadema, Brazil). The SIF consisted of $9 \mathrm{~g} / \mathrm{L}$ of sodium chloride that contained pancreatin and trypsin from bovine pancreas (Sigma-Aldrich, St. Louis, USA) at $10 \mathrm{~g} / \mathrm{L}$ each and $3 \mathrm{~g} / \mathrm{L}$ of bile salts (Oxgall, Difco, Hampshire, UK), and the $\mathrm{pH}$ was adjusted to 6.5 with sodium hydroxide (Synth, Diadema, Brazil). Survey assays were conducted at 0,60 and $120 \mathrm{~min}$ (SGF) and 0,90 and $180 \mathrm{~min}$ (SIF) of incubation.

\section{Evaluation of the stability of the microencapsulated microorganisms during storage}

This analysis was designed to determine the stability of the obtained microparticles during storage. The number of viable cells was counted after 1,30,60 and 90 days of storage at $-18^{\circ} \mathrm{C}, 7^{\circ} \mathrm{C}$ or $20^{\circ} \mathrm{C}$ (Oliveira et al., $2007 \mathrm{~b}$ ).

\section{Results and Discussion}

\section{Morphological characterization and mean diameter of the microparticles}

After atomization, a solidified and cooled freeflowing powder was collected. Optical microscopy of the powder revealed that microparticles or, more specifically, microspheres were produced. The microspheres were clearly multinucleate, and the probiotic suspension was evenly distributed within the entire volume of the particle, which exhibited a typical matrix structure. Because the process does not involve the evaporation of solvents, the microparticles produced were dense, non-porous and spherical (Figure 1A, 1B). The spherical shape is interesting because this format facilitates the flow of material, although it is not only shape that determines flowability. This shape was also observed by Savolainen et al. (2002) and Chambi et al. (2008) when they encapsulated drugs and watersoluble compounds by spray chilling with stearic acid or a mixture of stearic acid, lauric acid and sorbitan tristearate as the encapsulant agents, respectively.

SEM micrographs (Figure 1C, 1D) also revealed that although they were spherical in shape, the walls of the particles were irregular and quite wrinkled, which was attributed by Rodriguez et al. (1999) and Chambi et al. (2008) to the presence of stearic acid. Another possibility is that melting occurred during the transfer of the microparticles into the microscopy equipment, considering the relatively low melting point $\left(36.5^{\circ} \mathrm{C}\right)$ of the carrier.

The cells were not visible on the surface of the microparticles using SEM photomicrography, even at high magnification $(3.00 \mathrm{k} \mathrm{x})$. However, a small portion of the cells probably remained on the surfaces of microparticles, due to the matrix structure of the microparticles.

The size of the microcapsules is an important parameter that affects the sensory properties of foods; a larger particle size correlates with an increasingly detrimental effect on the food's texture. Hansen et al. (2002) suggested that a desirable size is approximately $100 \mu \mathrm{m}$. The laser diffraction confirmed the presence of different particles sizes with a fraction of which were smaller than $100 \mu \mathrm{m}$, however. The B. animalis subsp. lactis and L. acidophilus microparticles presented similar diameters, even with the different portions of reactivated cells:cocoa butter that were applied. The mean diameter of the $B$. animalis subsp. lactis microparticles was $44.4 \mu \mathrm{m}$, and the particle size ranged from 1.6 to $126.9 \mu \mathrm{m}$ (Figure 2A); the mean diameter of the L. acidophilus particles was $49.6 \mu \mathrm{m}$, and the size ranged from 2.2 to $126.9 \mu \mathrm{m}$ (Figure 2B).

\section{Resistance of $B$. animalis subsp. lactis and $L$. acidophilus to the microencapsulation process}

Because the microencapsulation of microorganisms is designed to increase the stability and viability of the probiotic culture in several types of products during processing and storage and in the presence of gastric and intestinal fluids, the choice of encapsulation method is critical (Favaro-Trindade and Grosso 2000; Favaro-Trindade and Grosso 2002; Oliveira et al., 2007b). The techniques that are most commonly used in the microencapsulation of probiotics are emulsion, extrusion and spray drying (Favaro-Trindade et al., 2011). Spray chilling is a low-cost alternative for the protection of probiotic cultures, which could 

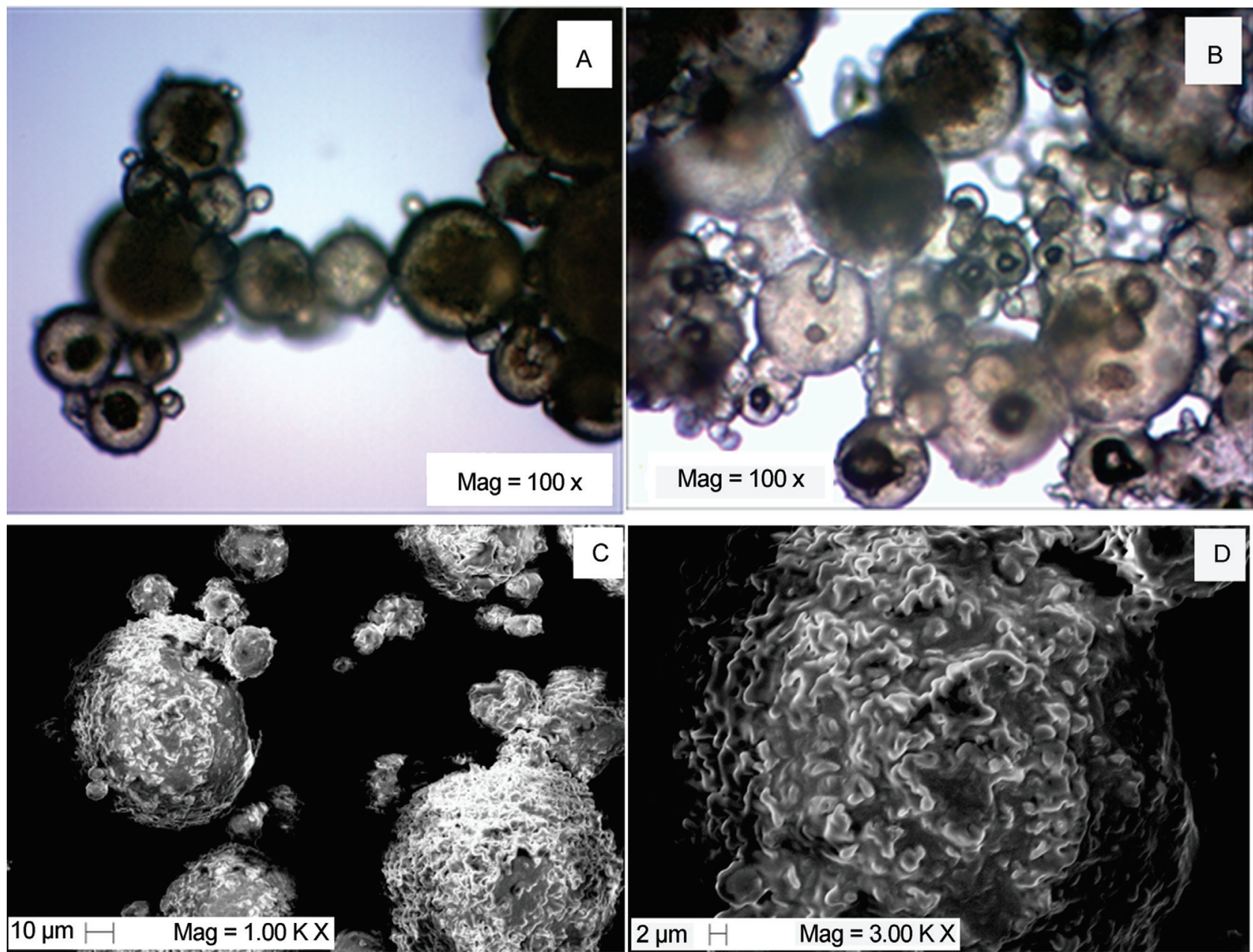

Figure 1 - Optical microscopy images of microparticles prepared by spray chilling containing B. animalis subsp. lactis (A) and L. acidophilus (B) and Scanning electron microscopy images of microparticles containing L. acidophilus.
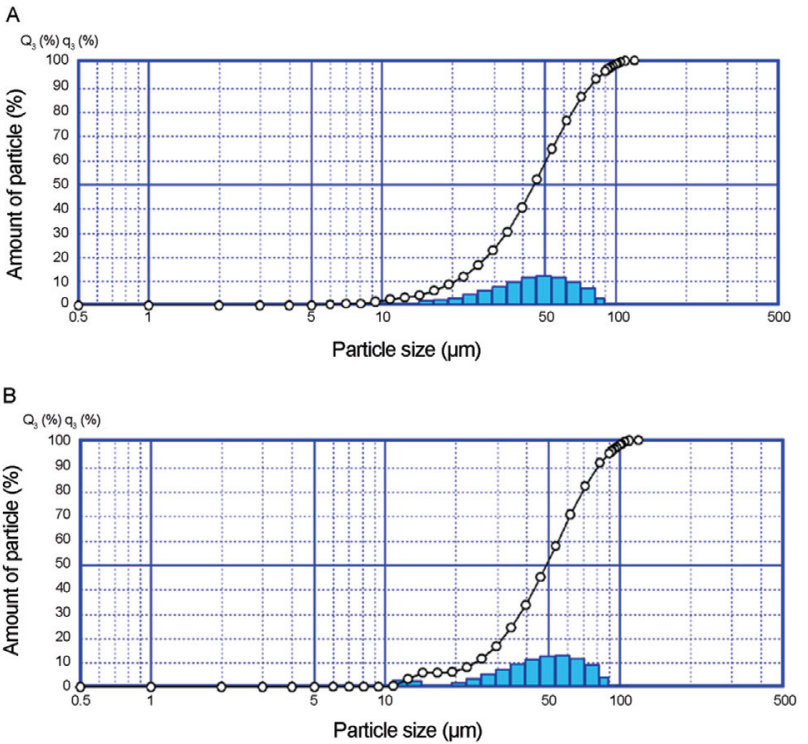

Figure 2 - Particle size distribution of the microparticles containing $B$. animalis subsp. lactis (A) and L. acidophilus (B) (bars = amount of particles; ${ }^{\circ}=$ cumulative distribution). expand the use of probiotics. However, little is known about the effects of microencapsulation on the viability of the cells and the protection of probiotics against external agents. Counts in the emulsion $\left(8.3 \log _{10} \mathrm{cfu} / \mathrm{g}\right.$ for $B$. animalis subsp. lactis; $6.5 \log _{10} \mathrm{cfu} / \mathrm{g}$ for $L$. acidophilus) and in the microcapsules $\left(8.2 \log _{10} \mathrm{cfu} / \mathrm{g}\right.$ for $B$. animalis subsp. lactis; $6.6 \log _{10} \mathrm{cfu} / \mathrm{g}$ for L. acidophilus) suggest that spray chilling did not affect the viability of the probiotics. The conditions that were employed in the process, such as atomization and chilling, were sufficiently mild to maintain the cellular integrity of the majority of the population.

Resistance of $B$. animalis subsp. lactis and $L$. acidophilus to simulated gastric and intestinal fluids

Before B. animalis subsp. lactis and L. acidophilus can be used as functional products, they must survive until they reach the gastrointestinal tract, pass through it, and colonise the intestine (Kim et al., 1988). However, one of the major problems in the efficacy of probiotic foods is the low survival rate of the microorganisms at gastric $\mathrm{pH}$ and in the high concentrations of bile salts in the intestine (Sabikhi 
et al., 2010). Figure 3 shows that both free and encapsulated cells of $B$. animalis subsp. lactis were resistant to SGF and SIF; only a 1.3 logarithmic cycle reduction in the population was observed during 5 hours of incubation. L. acidophilus reached the method detection limit $\left(10^{3} \mathrm{cfu} / \mathrm{g}\right)$ in $210 \mathrm{~min}$ in its free form. However, when this bacterium was encapsulated, $67 \%$ of the cells remained viable with a 2.7 logarithmic cycle reduction in the population during 5 hours of incubation. So, the solid lipid microparticles produced with cocoa butter offered protection to $L$. acidophilus into SGF and SIF. However the $33 \%$ of loss could be because of the heterogenic composition and low melting point of the cocoa butter. Some of its triglycerides may have melted at the temperature of this test $\left(37^{\circ} \mathrm{C}\right)$, causing premature release of the probiotics into the SGF. Therefore, considering the loss of viability of the encapsulated $B$. animalis subsp. lactis and L. acidophilus, microparticles should contain a higher initial number of viable cells in order to have an appropriate number of cells released into the intestine or microparticles should be produced with a lipid matrix with higher melted point.

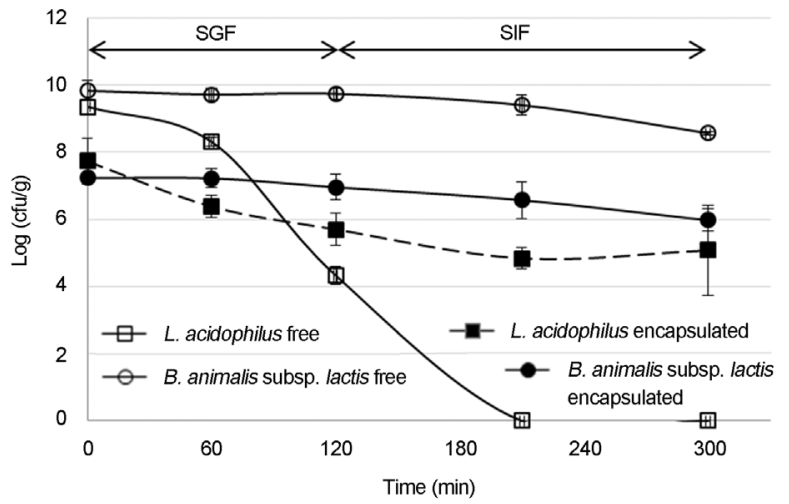

Figure 3 - Survival of free and encapsulated cells of $B$. animalis subsp. lactis and L. acidophilus after their exposure to simulated gastric fluid (SGF) and simulated intestinal fluid (SIF).
Other studies have confirmed the increase in the resistance of the microencapsulated probiotics when they are exposed to simulated gastric and intestinal fluids compared with the survival of free cells. L. acidophilus cells that were encapsulated in sodium alginate were more resistant than the free cells when they were submitted to tests that simulated gastric and intestinal conditions in vitro (Kim et al., 2008; Mokarram et al., 2009; Sabikhi et al., 2010). However, L. acidophilus that were encapsulated in calcium alginate (Favaro-Trindade and Grosso 2000) or in a mixture of alginate and starch Sultana et al. (2006) were not more resistant than the free cells when they were submitted to tests that simulated the stomach acidity and bile conditions in vitro.

\section{Stability of the microencapsulated microorganisms during storage}

Cell damage and a loss of activity may occur during the processing and storage of the cells. Therefore, a suitable microencapsulation process should ensure that the microorganisms survive processing and remain viable during storage (Oliveira et al., $2007 \mathrm{a}$ and b).

In the present study, according to results that are presented in Table 1, the free $B$. animalis subsp. lactis population was unstable during storage; it displayed logarithmic cycle reductions of $2.2\left(20^{\circ} \mathrm{C}\right), 7.6\left(7^{\circ} \mathrm{C}\right)$ and $4.6\left(-18^{\circ} \mathrm{C}\right)$ $\log \mathrm{cfu} / \mathrm{g}$. Inactivation during storage can be related to a number of factors, such as the formation of free radicals in the presence of oxygen, fatty acid oxidation, and DNA damage (Castro et al., 1997). Microencapsulation did not improve the stability of $B$. animalis subsp. lactis when the microparticles were stored at $20^{\circ} \mathrm{C}$. However, the encapsulated cells were more stable at $7{ }^{\circ} \mathrm{C}$, where $72 \%$ of the cells remained viable after 90 days of storage, and at $-18^{\circ} \mathrm{C}$, where the microparticle assured a minimum level of $10^{6} \mathrm{cfu} / \mathrm{g}$ for 90 days (Brasil, 2000).

The population of free and encapsulated cells of $L$. acidophilus decreased drastically during 90 days of storage

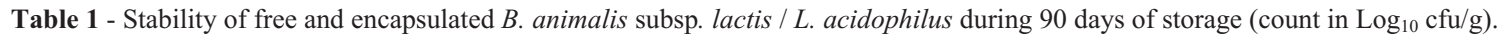

\begin{tabular}{|c|c|c|c|c|c|c|c|}
\hline \multirow[b]{2}{*}{ Microorganism } & \multirow[t]{2}{*}{ Time (days) } & \multicolumn{3}{|c|}{ Free } & \multicolumn{3}{|c|}{ Encapsulated } \\
\hline & & $20^{\circ} \mathrm{C}$ & $7^{\circ} \mathrm{C}$ & $-18^{\circ} \mathrm{C}$ & $20^{\circ} \mathrm{C}$ & $7^{\circ} \mathrm{C}$ & $-18^{\circ} \mathrm{C}$ \\
\hline \multirow[t]{4}{*}{ B. animalis subsp. lactis } & 0 & $10.0 \pm 0.0^{\mathrm{A}}$ & $10.0 \pm 0.2^{\mathrm{A}}$ & $10.0 \pm 0.2^{\mathrm{A}}$ & $7.1 \pm 0.1^{\mathrm{A}}$ & $7.4 \pm 0.1^{\mathrm{A}}$ & $7.4 \pm 0.1^{\mathrm{A}}$ \\
\hline & 30 & $8.3 \pm 0.1^{\mathrm{B}}$ & $10.7 \pm 0.4^{\mathrm{A}}$ & $9.7 \pm 0.1^{\mathrm{B}}$ & $5.1 \pm 0.1^{\mathrm{B}}$ & $6.5 \pm 0.2^{\mathrm{B}}$ & $7.2 \pm 0.1^{\mathrm{A}}$ \\
\hline & 60 & $8.5 \pm 0.1^{\mathrm{B}}$ & $6.1 \pm 0.2^{\mathrm{B}}$ & $5.0 \pm 0.1^{\mathrm{D}}$ & $5.3 \pm 0.2^{\mathrm{B}}$ & $5.3 \pm 0.0^{\mathrm{C}}$ & $8.1 \pm 0.9^{\mathrm{A}}$ \\
\hline & 90 & $7.8 \pm 0.1^{\mathrm{C}}$ & $2.4 \pm 0.1^{\mathrm{C}}$ & $5.4 \pm 0.3^{\mathrm{C}}$ & $3.8 \pm 0.1^{\mathrm{C}}$ & $5.2 \pm 0.1^{\mathrm{C}}$ & $7.3 \pm 0.1^{\mathrm{A}}$ \\
\hline \multirow[t]{4}{*}{ L. acidophilus } & 0 & $9.4 \pm 0.1$ & $9.5 \pm 0.1^{\mathrm{A}}$ & $9.5 \pm 0.1^{\mathrm{A}}$ & $8.2 \pm 0.1^{\mathrm{A}}$ & $8.2 \pm 0.1^{\mathrm{A}}$ & $8.2 \pm 0.1^{\mathrm{B}}$ \\
\hline & 30 & $\mathrm{ND}^{*}$ & $5.0 \pm 0.1$ & $8.4 \pm 0.1^{\mathrm{B}}$ & $3.9 \pm 0.2^{\mathrm{B}}$ & $4.1 \pm 0.1^{\mathrm{B}}$ & $8.3 \pm 0.2^{\mathrm{B}}$ \\
\hline & 60 & $\mathrm{ND}^{*}$ & $\mathrm{ND}^{*}$ & $2.0 \pm 0.0^{\mathrm{C}}$ & $2.6 \pm 0.1^{\mathrm{C}}$ & $3.7 \pm 0.1^{\mathrm{C}}$ & $8.6 \pm 0.1^{\mathrm{A}}$ \\
\hline & 90 & $\mathrm{ND}^{*}$ & $\mathrm{ND}^{*}$ & $3.5 \pm 0.2^{\mathrm{D}}$ & $1.6 \pm 0.2^{\mathrm{D}}$ & $1.5 \pm 0.0^{\mathrm{D}}$ & $6.6 \pm 0.1^{\mathrm{C}}$ \\
\hline
\end{tabular}

${ }^{*} \mathrm{ND}=$ no detected cells.

${ }^{\mathrm{A}, \mathrm{B}}$ Different letters in the same column, statistically show significant difference among values, $(\mathrm{p}>0.05)$. 
at $20^{\circ} \mathrm{C}$ and $7{ }^{\circ} \mathrm{C}$; the viable free cells were not detected (with limit method detection of $10 \mathrm{cfu} / \mathrm{g}$ ) after 30 and 60 days of storage, respectively. Moreover only $20 \%$ of the encapsulated cells remained viable after 90 days of storage at $7{ }^{\circ} \mathrm{C}$ (Table 1). A study by Oliveira et al. (2007b) showed that $L$. acidophilus displayed greater viability at a storage temperature of $7{ }^{\circ} \mathrm{C}$; however, in this work, the microcapsules were dehydrated. The probiotics that were encapsulated by complex coacervation and were dehydrated by spouted bed showed viability when they were stored at $7{ }^{\circ} \mathrm{C}$ for 120 days, but they showed a loss in viability prior to 90 days of storage at $37^{\circ} \mathrm{C}$. In the present study, promising results were observed with freezing conditions, which assured 90 days of shelf life; in these conditions, microencapsulation increased the L. acidophilus viability from $36.6 \%$ (free cells) to $81.1 \%$ (microencapsulated cells). These results allow us to conclude that only freezing conditions provided a long and satisfactory microparticle shelf life. This result was probably observed because in these conditions, the cells are in a latent state. In freezing temperatures as $-18{ }^{\circ} \mathrm{C}$, the molecular mobility is low, the metabolic reactions occur more slowly and thus the microbial activity is very reduced. This result limits the application of these microparticles in food products. Because the microorganisms are metabolically active in the microparticles at $7{ }^{\circ} \mathrm{C}$ and $20{ }^{\circ} \mathrm{C}$, the production of such compounds as metabolic acids and bacteriocins or the absence of subtracts may cause inactivation of the viable cells in the microparticles.

The present study shows that spray chilling with cocoa butter as a carrier to produce solid lipid microparticles was efficient in protecting the probiotics against the passage through gastric and intestinal fluids, and they could also be stored at freezing temperatures. In addition, the morphologies and sizes of the microparticles may facilitate the flow of material and would probably cause no harmful effects to food texture. Therefore, this method is an innovative matrix for the application of probiotics at low cost with the potential of scaling up. Other advantages are the use of low temperatures, the absence of organic solvents and the possible release of probiotics in the intestine during the digestion of the cocoa butter.

A future challenge in further studies is to choose a carrier or a process operation condition that improves the viability of the cells at refrigerated and room temperatures to increase the use of these microparticles in food products and to facilitate their storage.

\section{Acknowledgments}

The authors thank FAPESP in Brazil for their financial support (Process 2009/11713-2) and the scholarship that was granted (Process 2009/03140-2). The microorganisms and fat were kindly provided by Danisco (Brazil) and Emfal (Brazil), respectively.

\section{References}

Brazil, Ministério da Agricultura, Pecuária e Abastecimento (2000) Padrão de identidade e qualidade de leites fermentados. Resolução n. 05, de 13 de novembro de 2000. Brasília, 2000. Available at: http://extranet.agricultura.gov.br/ sislegis-consulta/consultarLegislacao.do?operacao=visuali zar\&id $=3285$.

Castro HP, Teixeira PM Kirby R (1997) Evidence of membrane damage in Lactobacilus bulgaricus following freeze drying. J Appl Microbiol 82:87-94.

Chambi HNM, Alvim ID, Barrera-Arellano D, Grosso CRF (2008) Solid lipid microparticles containing water-soluble compounds of different molecular mass: Production, characterization and release profiles. Food Res Int 41:229-236.

Champagne CP, Fustier P (2007) Microencapsulation for the improved delivery of bioactive compounds into foods. Food Biotechnol18:184-190.

de Vos P, Faas MM, Spasojevic M, Sikkema J (2010) Encapsulation for preservation of functionality and targeted delivery of bioactive food components. Int Dairy J20:292-302.

FAO/WHO (2006) Probiotics in food. Health and nutritional properties and guidelines for evaluation, FAO Food and Nutrition Paper No. 85. World Health Organization and Food and Agriculture Organization of the United Nations, Rome.

Favaro-Trindade CS, Grosso CRF (2000) The effect of the immobilization of Lactobacillus acidophilus and Bifidobacterium lactis in alginate on their tolerance to gastro-intestinal secretions. Milchwissenschaft 55:496-499.

Favaro-Trindade CS, Grosso CRF (2002) Microencapsulation of L. acidophilus (La-05) and B. lactis (Bb-12) and evaluation of their survival at the $\mathrm{pH}$ values of the stomach and in bile. $\mathrm{J}$ Microencapsul19:485-494.

Favaro-Trindade CS , Heinemann RJB, Pedroso DL (2011) Developments in probiotic encapsulation. CAB Reviews: Perspectives in Agriculture, Veterinary Science, Nutrition and Natural Resources 6:1-8.

Fung WY, Yuen KH, Liong MT (2011) Agrowaste-based nanofibers as a probiotic encapsulant: fabrication and characterization. J Agric Food Chem 59:8140-8147.

Gbassi GK, Vandamme T, Ennahar S, Marchioni E (2009) Microencapsulation of Lactobacillus plantarum spp in an alginate matrix coated with whey proteins. Int J Food Microbiol 129:103-105.

Gouin S (2004) Microencapsulation: industrial appraisal of existing technologies and trends. Trends Food Sci Technol 15:330-347.

Grosso CRF, Favaro-Trindade CS (2004). Stability of free and immobilized Lactobacillus acidophilus and Bifidobacterium lactis in acidified milk and immobilized B. lactis in yoghurt. Braz J Microbiol 35:151-156.

Hansen LT, Allan-Wojtas PM, Jin LA, Paulson AT (2002) Survival of Ca-alginate microencapsulated Bifidobacterium spp. in milk and simulated gastrointestinal conditions. Food Microbiol 19:35-45.

Kim HS, Kamara BJ, Good IC, Enders Jr GI (1988) Method for the preparation of stabile microencapsulated lactic acid bacteria. J Ind Microbiol 3:253-257.

Kim SJ, Cho SY, Kim SH, Song OJ, Shin S, Cha DS, Park HJ (2008) Effect of microencapsulation on viability and other characteristics in Lactobacillus acidophilus ATCC 43121. LWT - Food Sci Technol 41:493-500. 
Kwok KK,Groves MJ, Burgess DJ (1992) A novel method for the determination of sterility of microparticles and measurement of viability of encapsulated organisms. Pharmac Res 13:410-413.

Lahtinen SJ, Ouwehand AC, Salminen SJ, Forssell P, Myllärinen P (2007) Effect of starch and lipid-based encapsulation on the culturability of two Bifidobacterium longum strains. Lett Appl Microbiol 44:500-5.

Liserre AM, Ré MI, Franco BDGM (2007) Microencapsulation of Bifidobacterium animalis subsp. lactis in modified alginate-chitosan beads and evaluation of survival in simulated gastrointestinal conditions. Food Biotechnol 21:1-16.

Mokarram RR, Mortazavi SA, Habibi Najafi MB, Shahidi F (2009) The influence of multi stage alginate coating on survivability of potential probiotic bacteria in simulated gastric and intestinal juice. Food Res Int 42:1040-1045.

Okuro PK, Baliero JCC, Liberal RDCO, Favaro-Trindade CS (2013a) Co-encapsulation of Lactobacillus acidophilus with inulin or polydextrose in solid lipid microparticles provides protection and improves stability. Food Res Int 53:96-103.

Okuro PK, Matos Jr FE, Favaro-Trindade CS (2013b) Technological Challenges for Spray-Chilling Encapsulation of Functional Food Ingredients. Food Technol Biotechnol 51:171182.

Oliveira AC, Moretti TS, Boschini C, Balieiro JCC, Freitas O, Favaro-Trindade CS (2007a) Stability of microencapsulated B. lactis (BI 01) and L. acidophillus (LAC 4) by complex coacervation followed by spray drying dehydration. J Microencapsul 24:685-693.

Oliveira Oliveira AC, Moretti TS, Boschini C, Balieiro JCC, Freitas LAP,Freitas O, Favaro-Trindade CS (2007b) Microencapsulation of B. lactis (BI 01) and L. acidophilus (LAC 4) by complex coacervation followed by spouted-bed drying. Dry Technol 25:1687-1693.
Pedroso DL, Thomazini M, Heinemann RJB, Favaro-Trindade CS (2012) Protection of Bifdobacterium lactis and Lactobacillus acidophilus by microencapsulation using spraychilling. Int Dairy J 26:127-132.

Rodriguez L, Passerini N, Cavallari C, Cini M, Sancin P, Fini A (1999) Description and preliminary evaluation of a new ultrasonic atomizer for pray-73 congealing processes. Int $\mathrm{J}$ Pharm 183:133-143.

Rokka S, Rantamaki, P. (2010). Protecting probiotic bacteria by microencapsulation: challenges for industrial applications. Eur Food Res Technol 231, 1-12.

Sabikhi L, Babu R, Thompkinson DK, Kapila S (2010) Resistance of microencapsulated Lactobacillus acidophilus LA1 to processing treatments and simulated gut conditions. Food Bioprocess Technol 3:586-593.

Sato K, Ueno S (2005) Polymorphism in fats and oils. Industrial oil and fat products edible oil and fat products: Chemistry properties and health effects. Inc F. Shahidi Ed., New York, USA.

Savolainen M, Khoo C, Glad H, Dahlqvist C, Juppo AM (2002) Evaluation of controlled-release polar lipid microparticles. Int J Pharm 244:151-161.

Sultana K, Godward G, Reynolds N, Arumugaswamy R Peiris P, Kailasapathy K (2006) Encapsulation of probiotic bacteria with alginate-starch and evaluation of survival in simulated gastrointestinal conditions and in yoghurt. Int J Food Microbiol 62:47-55.

Westesen K, Bunjes H, Koch MHJ (1997) Physicochemical characterization of lipid nanoparticles and evaluation of their drug loading capacity and sustained release potential. J Control Release 48:223-236.

All the content of the journal, except where otherwise noted, is licensed under a Creative Commons License CC BY-NC. 